\title{
PERBANDINGAN AKTIVITAS ANTIOKSIDAN EKSTRAK APEL HIJAU (Malus domestica) SEGAR DAN KERING DENGAN METODE SPEKTROFOTOMETRI
}

\author{
Youstiana Dwi Rusita, Ratih Purwasih, Regia Desty Rakhmayanti \\ Kementerian Kesehatan Politeknik Kesehatan Surakarta Jurusan Anafarma
}

\begin{abstract}
Green apples containing antioxidants substance that has beneficial effect in skin health. Green apples containing catechin, epicatechin, ploridzin, quercetin, ellergic acid and chlorogenic acid. One of food processing is hot drying, hot drying can influence bioactive substance in the food. The aim of this study is to measure antioxidant activity of fresh and dry green apple extract. Design of this study is experimental design, independent variable of this study is hot drying, and dependent variable of this study is antioxidant activity level. Extraction method using ultrasonic maseration, hot drying using oven. Antioxidant activity measuring using spectrophotometry method. IC50 level of fresh green apple extract is 31.26 ppm, IC50 of dry green apple extract is $52.36 \mathrm{ppm}$. IC50 level of fresh green apple extract are less than $50 \mathrm{ppm}$ and IC50 level of dry green apple extract are more than $500 \mathrm{ppm}$. Conclusion of this study is fresh green apple extract has strong antioxidant activity and dry green apple extract has very strong antioxidant activity.
\end{abstract}

Keywords: green apple, antioxidant activity

Buah-buahan merupakan sumber bahan alami yang mengandung berbagai senyawa antioksidan tinggi. Dibandingkan dengan antioksidan sintetis, antioksidan alami umumnya lebih aman untuk dikonsumsi dan dapat meningkatkan derajat kesehatan tubuh. Indonesia merupakan salah satu dari delapan pusat keanekaragaman genetika tanaman dunia, khususnya buah-buahan tropis yang berpotensi sebagai sumber antioksidan alami. (Novi, dkk. 2016). Salah satu tanaman yang berpotensi memiliki khasiat sebagai antioksidan adalah tanaman apel (Yuniarto, dkk., 2014).

Apel merupakan salah satu buah yang banyak dikonsumsi oleh penduduk Indonesia. berdasarkan data dari Biro Pusat Statistik menunjukkan bahwa pada tahun 1985-1987 rata-rata konsumsi apel masyarakat Indonesia meningkat $0,02 \%$ tiap tahun dengan rata-rata konsumsi apel 0,6 kg/kapita/tahun, sedangkan pada tahun 2006 rata-rata konsumsi apel di Indonesia mencapai $1,1 \mathrm{~kg} / \mathrm{kapita} / \mathrm{tahun}$ (Huda, dkk., 2015).

Apel hijau banyak mengandung vitamin, seperti vitamin $\mathrm{A}, \mathrm{B}, \mathrm{C}$, mineral, serat serta senyawa flavonoid salah satunya kuersetin (Suparni dan Wulandari, 2012; Jauhary, 2016). Menurut penelitian Maalik dkk. (2014) quersetin adalah suatu molekul serbaguna, contohnya sebagai antioksidan, neurologikal, antivirus, anti inflamasi, hepatoprotektif, melindungi sisterm reproduksi tubuh dan agen anti obesitas. Kemampuan flavonoid sebagai antioksidan belakangan ini banyak diteliti, karena flavonoid memiliki kemampuan untuk merubah atau 
mereduksi radikal bebas dan juga sebagai anti radikal bebas (Tarigan dkk.,2008 dalam Ikhlas, 2013).

Buah apel hijau mengandung zat antioksidan yang sangat bagus untuk kesehatan kulit. Kandungan antioksidan yang sangat tinggi juga menjadi alasan tingginya konsumsi buah apel oleh masyarakat sebagai upaya pencegahan terhadap penyakit dan disfungsi kesehatan tubuh lainnya (Baskara, 2010).

Pengeringan adalah proses yang dilakukan dengan tujuan untuk mengawetkan dan memperpanjang masa simpan suatu bahan pangan. Pengeringan dapat dilakukan dengan menggunakan panas buatan ataupun dengan menjemur pada sinar matahari langsung. Pengeringan pada apel dimaksudkan untuk membuang sejumlah air untuk menjamin penyimpanan dan mencegah terjadinya reaksi enzimatis pada apel (Widyasari, 2000). Pengolahan dengan penggunaan panas pada bahan pangan dapat mempengaruhi komponen bioaktif baik secara positif maupun negatif. Pengaruh positif terjadi pada pengeringan buah delima dengan oven bersuhu 40,60, dan $\quad 80 \quad{ }^{0} \mathrm{C}$ yang menunjukkan peningkatan kandungan vitamin $\mathrm{C}$, dan aktivitas antioksidan (Mphahlele, dkk., 2016). Namun, pengaruh negatif terjadi pada pengeringan oven tanaman pegagan yang menunjukkan penurunan kandungan total flavonoid sebesar 76\%. (Zainol dkk., 2009). Pengaruh negatif juga terjadi pada pengeringan kunyit yang menyebabkan penurunan aktivitas antioksidan dan total fenol (Chan dkk., 2009).

Pengaruh proses pengeringan berbeda-beda dipengaruhi oleh bahan pangan yang dikeringkan dan aktivitas biologis yang diuji. Berdasarkan uraian tersebut, maka dilakukan penelitian ini untuk mengetahui pengaruh proses pengeringan terhadap aktifitas antioksidan pada buah apel.

\section{METODE PENELITIAN}

Alat yang digunakan dalam penelitian ini adalah seperangkat alat maserasi, timbangan analitik, peralatan gelas laboratorium, vortex, spektrofotometer UV-Vis, mikropipet, pipet filler.

Bahan yang digunakan dalam penelitian antara lain buah apel hijau, etanol 96\%, etanol 70\%, akuades, kuersetin, DPPH (Difenil-1-Pikril Hidrazil), kuersetin, alumunium foil, kertas saring.

\section{Prosedur Ekstraksi}

Sebanyak 10 buah apel hijau diiris tipis dan kotak-kotakdan dihomogenkan. Selanjutnya hasil ditimbang sebanyak 25 gram dan diulangi lima kali. Dari Masing-masing letakkan dalam nampan plastik dan ratakan hingga tipis. Untuk sisa nomor 1.3, ambil kurang lebih 250 gram letakkan dalam nampan dan ratakan hingga tipis (utk mempercepat pengeringan). Masukkan dalam Oven pada suhu $45^{\circ} \mathrm{C}$ selama kurang lebih 24 jam. Sampel didinginkan sampai suhu ruang, Timbang berat masing-masing dari 5 kali ulangan penimbangan 25 gram berat basah. Catat berat masing-masing (sebagai berat kering). Blender sampel yang sudah dikeringkan.

Timbang sampel kering yang sudah dihaluskan dan sisa sampel basah yang sudah dipotong-potong sebanyak 100 gram. Masing-masing masukkan dalam blender dan tambahkan ethanol $70 \%$ sebanyak $600 \mathrm{~mL}$. Blender kurang lebih 5 menit (untuk sampel basah sampel halus) dan dimasukkan dalam beker gelas $1000 \mathrm{~mL}$ 
Digesti dengan alat ultrasonik $50 \mathrm{kHz}$ pada suhu $35{ }^{\circ} \mathrm{C}$ selama 30 kemudian mengikat cmekatkan dengan rotary evaporator pada suhu $50{ }^{\circ} \mathrm{C}$, dilanjutkan dengan waterbath pada suhu $60^{\circ} \mathrm{C}$ sampai pekat (jika ditimbang massa konstan).

Rendemen dihitung dengan rumus:

$$
\text { Rendemen }(\%)=\frac{M e}{M s} \times 100 \%
$$

\section{Penentuan kadar kuersetin}

Kadar kuersetin ditentukan dengan menggunakan spektrofotometer UV-Vis. Dibuat deret larutan standar kuersetin dengan konsentrasi sebesar 5, 10, 15, 20, dan 25 ppm kemudian diukur absorbansinya menggunakan spektrofotometer UV-Vis pada panjang gelombang $210 \mathrm{~nm}$. Adapun sampel ekstrak apel hijau segar (I) dan kering (II) diambil 0,05 g dan dilarutkan dalam 250 $\mathrm{mL}$ diukur absorbansinya pada panjang gelombang $210 \mathrm{~nm}$ menggunakan spektrofotometer UV-Vis.

\section{Uji aktivitas Antioksidan}

Uji aktivitas antioksidan penangkap radikal pada ekstrak apel dilakukan dengan metode DPPH menggunakan spektrofotometer UV-Vis. Ekstrak apel diencerkan kembali pada etanol (1000 ppm) pada berbagai konsentrasi yang berbeda $(5,10,15,20$ dan $25 \mathrm{ppm}$ ) untuk setiap sampel yang digunakan. Setiap $2 \mathrm{~mL}$ larutan akhir terdiri dari $1 \mathrm{~mL}$ ekstrak dan $1 \mathrm{~mL}$ larutan DPPH (125 $\mu \mathrm{M}$ dalam ethanol). Larutan kemudian divorteks dan didiamkan pada suhu $37{ }^{\circ} \mathrm{C}$ selama 30 menit pada ruangan gelap. Penyerapan sinar oleh larutan diukur pada panjang gelombang $517 \mathrm{~nm}$ menggunakan spektrofotometri. Larutan DPPH tanpa sampel dan tanpa standar digunakan sebagai kontrol. Quercetin digunakan untuk membuat kurva standar. Dibuat konsentrasi sebesar ( 2, 4, 10, 20 dan 30 ppm). Aktivitas penangkapan radikal DPPH dinyatakan sebagai \% penghambatan terhadap radikal DPPH. Persentase penghambatan dihitung dengan persamaan:

$\%$ penghambatan $=\frac{(\boldsymbol{A}-\boldsymbol{B})}{\boldsymbol{A}} \times \mathbf{1 0 0} \%$

Keterangan:

$\mathrm{A}=$ absorbansi tanpa penambahan sampel/standar (DPPH dan ethanol) $\mathrm{B}=$ absorbansi dengan penambahan sampel/ standar (DPPH, ethanol dan sampel/standar)

Data yang diperoleh dari penelitian ini yaitu data kuantitatif yang diperoleh melalui pengamatan dan pengukuran parameter yang diuji. Data kuantitatif berupa hasil pengukuran aktivitas antioksidan.

\section{HASIL DAN PEMBAHASAN}

Ekstrak apel hijau yang digunakan diperoleh dari ekstrak apel hijau segar (I) dan apel hijau kering (II). Ekstrak diperoleh dengan cara maserasi sonikasi. Dengan maserasi sonikasi diharapkan ekstrak yang dihasilkan tinggi. Dari hasil ekstraksi diperoleh rendemen ekstrak I dan ekstrak II sebesar 58,78 dan 35,63\%. Selanjutnya dilakukan uji aktivitas antioksidan terhadap ekstrak apel hijau segar dan apel hijau kering.

Uji aktivitas antioksidan dilakukan dengan metode DPPH menggunakan Spektrofotometer UV-Vis, dimana standar atau sampel direaksikan dengan DPPH yang bertindak sebagai radikal bebas. Aktivitas antioksidan diukur dari kemampuan zat antioksidan dalam menghambat radikal bebas, yang ditunjukkan dengan selisih absorbansi antara kontrol dan sampel/standar terhadapabsorbansi kontrol.

Kandungan quercetin dalam apel hijau tinggi, sehingga yang akan diuji 
adalah aktivitas antioksidan quercetin. Uji aktivitas antioksidan mula-mula dilakukan dengan uji aktivitas antioksidan standar quercetin. Hasil uji aktivitas antioksidan standar quercetin dapat dilihat pada Tabel 1. Dari tabel terlihat bahwa semakin besar konsentrasi quercetin maka aktivitas antioksidan (\%inhibisi) semakin tinggi. Dari data diperoleh persamaan garis $\mathrm{y}=1,4832 \mathrm{x}+$ 46,859 dengan $\mathrm{R}^{2}=0,8181$.

Tabel 1. Uji aktivitas antioksidan standar quercetin

\begin{tabular}{ccccc}
\hline No & $\begin{array}{c}\text { Quercetin } \\
(\mathrm{ppm})\end{array}$ & $\begin{array}{c}\text { Absorbansi } \\
\text { standar }\end{array}$ & $\begin{array}{c}\text { Absorbansi } \\
\text { kontrol }\end{array}$ & $\begin{array}{c}\% \\
\text { inhibisi }\end{array}$ \\
\hline 1 & 2 & 0,961 & 0,538 & 40,12 \\
2 & 4 & 0,954 & 0,399 & 53,58 \\
3 & 10 & 0,953 & 0,23 & 71,17 \\
4 & 20 & 0,954 & 0,121 & 82,72 \\
5 & 30 & 0,955 & 0,104 & 84,61 \\
\hline
\end{tabular}

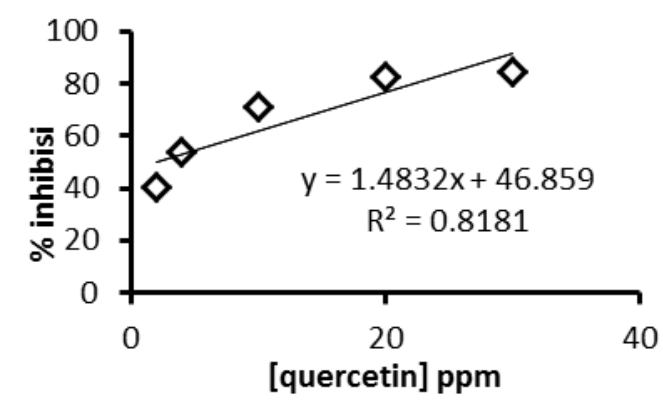

Gambar 1. Kurva standar quercetin

Selanjutnya dilakukan uji aktivitas antioksidan terhadap ekstrak apel hijau segar dan apel hijau kering. Hasil uji aktivitas antioksidan ekstrak apel hijau segar (I) dapat dilihat pada Tabel 2, sedangkan hasil uji aktivitas antioksidan ekstrak apel hijau kering (II) dapat dilihat pada Tabel 3.
Tabel 2. Uji aktivitas antioksidan ekstrak apel hijau segar (I).

\begin{tabular}{ccccc} 
No & $\begin{array}{c}\text { Ekstrak I } \\
(\mathrm{ppm})\end{array}$ & $\begin{array}{c}\text { Absorbansi } \\
\text { sampel }\end{array}$ & $\begin{array}{c}\text { Absorbansi } \\
\text { kontrol }\end{array}$ & $\begin{array}{c}\% \\
\text { inhibisi }\end{array}$ \\
\hline 1 & 5 & 0,915 & 0,999 & 8,31 \\
2 & 10 & 0,833 & 0,999 & 16,52 \\
3 & 15 & 0,796 & 0,999 & 20,22 \\
4 & 20 & 0,674 & 0,999 & 32,43 \\
5 & 25 & 0,590 & 0,999 & 40,84 \\
\hline
\end{tabular}

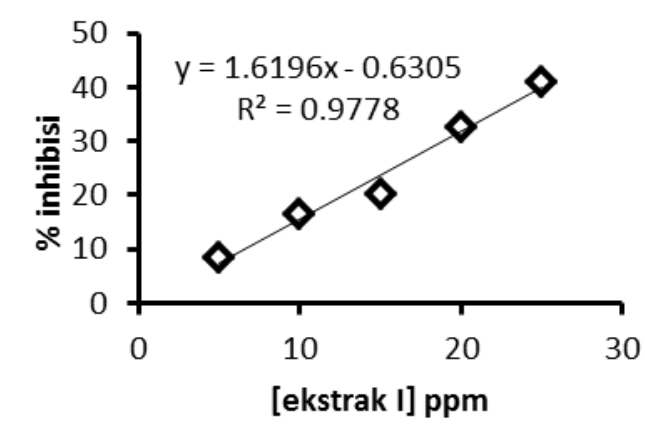

Gambar 2. Kurva \% inhibisi ekstrak apel hijau segar

Tabel 3. Uji aktivitas antioksidan ekstrak apel hijau segar (I)

\begin{tabular}{ccccc} 
No & $\begin{array}{c}\text { Ekstrak } \\
\text { II }\end{array}$ & $\begin{array}{c}\text { Absorbansi } \\
\text { sampel }\end{array}$ & $\begin{array}{c}\text { Absorbansi } \\
\text { kontrol }\end{array}$ & $\begin{array}{c}\% \\
\text { inhibisi }\end{array}$ \\
\hline 1 & 5 & 0,992 & 0,999 & 0,60 \\
2 & 10 & 0,898 & 0,999 & 10,01 \\
3 & 15 & 0,845 & 0,999 & 15,32 \\
4 & 20 & 0,818 & 0,999 & 18,02 \\
5 & 25 & 0,785 & 0,999 & 21,32 \\
\hline
\end{tabular}

Berdasarkan Tabel 2 dan 3 terlihat perbandingan \% inhibisi (aktivitas antioksidan quercetin pada ekstrak apel hijau segar dan kering, bahwa aktivitas antioksidan ekstrak apel hijau segar lebih 
tinggi daripada apel hijau kering dengan konsentrasi yang sama.

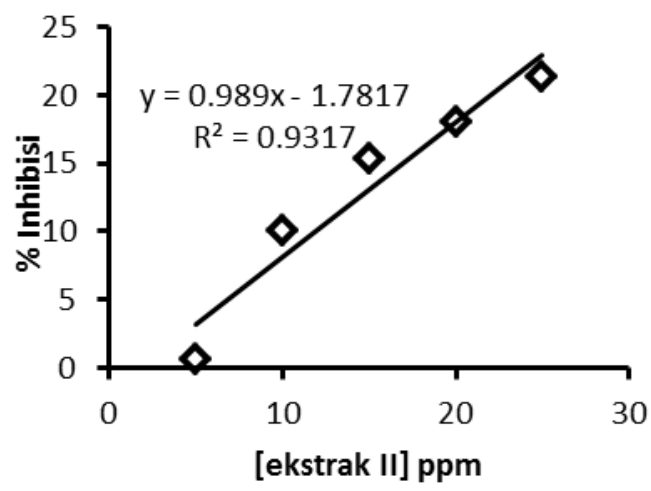

Gambar 3. Kurva \% inhibisi ekstrak apel hijau kering

Aktivitas antioksidan dari standar maupun sampel dapat dilihat dari perhitungan IC50 berdasarkan data \%inhibisi, dimana semakin rendah nilai IC50 maka semakin baik aktivitas antioksidan dari sampel/standar. Nilai IC50 diperoleh dengan mengeplotkan \%inhibisi 50 pada persamaan garis yang diperoleh dari masing-masing pengukuran (\%inhibisi vs konsentrasi). Berdasarkan Gambar 1 diperoleh persamaan garis $\mathrm{y}=$ $1,4832 x+46,859$ dengan $R^{2}=0,8181$. Dari data tersebut untuk standar quercetin memiliki $\mathrm{IC}_{50}$ sebesar 2,12 ppm. Sedangkan untuk ekstrak apel hijau I berdasarkan persamaan garis $\mathrm{y}=1.6196 \mathrm{x}$ - 0.6305 memiliki $\mathrm{IC}_{50}$ sebesar 31,26 ppm dan untuk ekstrak apel kering berdasarkan pada persamaan garis $\mathrm{y}=0.989 \mathrm{x}-1.7817$ diperoleh IC50 sebesar 52,36 ppm. Berdasarkan data yang ada dapat digolongkan bahwa quercetin dan ekstrak I tergolong antioksidan yang sangat kuat karena $<50$ ppm, sedangkan ekstrak II tergolong zat antioksidan yang kuat.

\section{KESIMPULAN}

Dari penelitian yang telah dilakukan dapat disimpulkan bahwa standar quercetin memiliki IC50 sebesar 2,12 ppm. Sedangkan untuk ekstrak apel hijau I dan II memiliki IC50 sebesar 31,26 ppm dan 52,36 ppm. Berdasarkan data yang ada dapat digolongkan bahwa quercetin dan ekstrak I tergolong antioksidan yang sangat kuat karena $<50$ ppm, sedangkan ekstrak II tergolong zat antioksidan yang kuat.

\section{DAFTAR PUSTAKA}

Ashraff, M. A., M.J. Maah, I. Yusoff, K. Mahmood, A. Wajid, 2011, Study of Antioxidant Potential of Tropical Fruit, Int.Journal of Bioscience, Biochemistry and Bioinformatics,1(1) 53-57.

Depkes RI., 1979, Farmakope Indonesia, Edisi III, Departemen Kesehatan Republik Indonesia, Jakarta. 8, 65, 271,504.

Depkes. 1995. Materia Medika Indonesia. Jilid ke-VI. Jakarta: Departemen Kesehatan Republik Indonesia.

Depkes. 2000. Inventaris Tanaman Obat Indonesia (I). Jilid I. Jakarta: Departemen Kesehatan RI dan Kesejahteraan Sosial RI Badan Penelitian dan Pengembangan Kesehatan.

Febrianti, N., Yunianto, I., Dhaniaputri, R., 2016, Kandungan antioksidan asam askorbat pada buah-buahan tropis, Bio Wallacea Jurnal Ilmiah Ilmu Biologi, Vol. 2 No. 1, p. 1-5 ISSN: 2442-2622.

Gunawan, D. dan Mulyani, S. 2004. Ilmu obat alam (Farmakognosi). Jilid 1. Jakarta. Penerbit penebar swadaya. 
Harborne JB. 1987. Metode Fitokimia;

Penuntun cara Modern

Menganalisis Tumbuhan. Terbitan ke-2. Padmawinata K, Soediro I, penerjemah; Bandung: ITB. Terjemahan Dari: Phytochemical Methods.

Nurliyana, R., S. Zahir, M. Sulaeman, M.R. Aisyah, Rahim, K, 2010, Antioxidant Study of Pulps and Pelels of Dragon Fruit: A Comparative Study, International Food Research Journal, 17:367375

Pourcel, L., dan Routaboul, J,M., 2006, Flavonoid Oxidation In Plants: From Biochemical Properties To Physiological. Elsevier

Sastrohamidjojo H. 2004. Kimia Minyak Atsiri. Gadjah Mada University Press, Yogyakarta. Hal : 13-14.

Trevor R. 1995. Kandungan Organik Tumbuhan Tinggi. Penerjemah Kosasih Padmawinata. Bandung : Penerbit ITB.

Waji RA dan Sugrani A., 2009, Flavonoid (Quercetin)., Makalah. Tidak Diterbitkan, Program S2 Kimia Fakultas Matematika dan Ilmu Pengetahuan Alam Universitas Hasanuddin.

Widowati. W.. 2005. Penapisan aktivitas superoksid dismutase pada berbagai tanaman. JKM. 5(1) : 3334.

Yoshikawa, Masayuki, Matsuda H. 2006. Traditional Medicines for Modern Times Antidiabetic Plants : Saponin. CRC Press Rawlins, 2003) 